\title{
Torpor Patterns in Desert Hedgehogs (Paraechinus aethiopicus) Represent Another New Point along a Thermoregulatory Continuum
}

\author{
Justin G. Boyles ${ }^{1, *}$ \\ Nigel C. Bennett ${ }^{2,3}$ \\ Osama B. Mohammed ${ }^{2}$ \\ Abdulaziz N. Alagaili ${ }^{2}$ \\ ${ }^{1}$ Cooperative Wildlife Research Laboratory, Department of \\ Zoology, Southern Illinois University, Carbondale, Illinois; \\ ${ }^{2}$ King Saud University Mammals Research Chair, Department \\ of Zoology, College of Science, King Saud University, PO Box \\ 2455, Riyadh 11451, Saudi Arabia; ${ }^{3}$ Mammal Research Institute, \\ Department of Zoology and Entomology, University of Pretoria, \\ Pretoria 0002, South Africa
}

Accepted 2/13/2017; Electronically Published 4/12/2017

\begin{abstract}
Documenting variation in thermoregulatory patterns across phylogenetically and geographically diverse taxa is key to understanding the evolution of endothermy and heterothermy in birds and mammals. We recorded body temperature $\left(T_{\mathrm{b}}\right)$ in free-ranging desert hedgehogs (Paraechinus aethiopicus) across three seasons in the deserts of Saudi Arabia. Modal $T_{\mathrm{b}}$ 's $\left(35^{\circ}-\right.$ $36.5^{\circ} \mathrm{C}$ ) were slightly below normal for mammals but still warmer than those of other hedgehogs. The single maximum $T_{\mathrm{b}}$ recorded was $39.2^{\circ} \mathrm{C}$, which is cooler than maximum $T_{\mathrm{b}}$ 's recorded in most desert mammals. Desert hedgehogs commonly used torpor during winter and spring but never during summer. Torpor bouts occurred frequently but irregularly, and most lasted less than $24 \mathrm{~h}$. Unlike daily heterotherms, desert hedgehogs did occasionally remain torpid for more than $24 \mathrm{~h}$, including one bout of $101 \mathrm{~h}$. Body temperatures during torpor were often within $2^{\circ}-3^{\circ} \mathrm{C}$ of ambient temperature; however, we never recorded repeated bouts of long, predictable torpor punctuated by brief arousal periods similar to those common among seasonal hibernators. Thus, desert hedgehogs can be included on the ever-growing list of species that display torpor patterns intermediate to traditionally defined hibernators and daily heterotherms. Extant hedgehogs are a recent radiation within an ancient family, and the intermediate thermoregulatory pattern displayed by desert hedgehogs is unlike the deeper and more regular torpor seen in other hedgehogs, suggesting that this may be a derived - as opposed to ancestral — trait in this subfamily.
\end{abstract}

*Corresponding author; e-mail: jgboyles@siu.edu.

Physiological and Biochemical Zoology 90(4):445-452. 2017. (C) 2017 by The University of Chicago. All rights reserved. 1522-2152/2017/9004-6169\$15.00. DOI: $10.1086 / 691542$
We suggest that this family (Erinaceidae) and order (Eulipotyphla) may be important for understanding the evolution of thermoregulatory patterns among Laurasiatheria and mammals in general.

Keywords: body temperature, Ethiopian hedgehog, Eulipotyphla, heterothermy, hibernation.

\section{Introduction}

Describing variation in thermoregulatory and body temperature $\left(T_{\mathrm{b}}\right)$ patterns and determining the distribution - both phylogenetically and geographically - of those patterns in mammals and birds is vital to understanding the evolutionary history of endothermy. Of special interest is how various derivations of heterothermy relate to the evolutionary history of endothermy. Patterns of heterothermy have often been considered distinct (Geiser 1998), with daily heterothermy and hibernation (seasonal heterothermy) differentiated by parameters including length of torpor bouts and metabolic rate during torpor (Geiser and Ruf 1995). Increased interest in the topic and advances in technology have led to an increase in research on species from tropical, subtropical, and desert regions, and exceptions that fall in-between the normal classifications of heterothermy are common enough (Lovegrove et al. 2001; Lovegrove and Genin 2008; Geiser and Mzilikazi 2011; Geiser and Martin 2013) that many researchers now view the metabolic plasticity between normothermy and hibernation as a continuum (Canale et al. 2012; Boyles et al. 2013; van Breukelen and Martin 2015) arising from ancestral heterothermy (Lovegrove 2012a).

Differentiating between the two competing views of heterothermy (distinct categories vs. a continuum) will become easier as more data on $T_{\mathrm{b}}$ of phylogenetically and geographically diverse species become available. One such phylogenetically important order is the Eulipotyphla (solenodons, shrews, moles, hedgehogs, and moonrats), which occupy an interesting (albeit contentious) position in the mammalian phylogeny (Mouchaty et al. 2000; Douady et al.2002). They are most commonly placed sister to the rest of Laurasiatheria (Douady et al. 2002; BinindaEmonds et al. 2007), diverging 75-85 million years ago (Douady and Douzery 2003; Hallström and Janke 2010). The Eulipotyphla have been singled out as important in understanding the evolution of heterothermy in mammals because of their early divergence from the other laurasiatherians (Lovegrove 2012b).

Among the Eulipotyphla, the thermal physiology of hedgehogs (subfamily Erinaceinae) has long interested researchers 
(Dmi'el and Schwarz 1984; Soivio et al. 1968). Hedgehogs typically maintain normothermic $T_{\mathrm{b}}$ between $33^{\circ}$ and $35^{\circ} \mathrm{C}$ (Shkolnik and Schmidt-Nielsen 1976; Fowler and Racey 1990; Król 1994; Hallam and Mzilikazi 2011), which is intermediate between monotremes, metatherians, and more basal placental mammals $\left(T_{\mathrm{b}}\right.$ of $30^{\circ}-33^{\circ} \mathrm{C}$; Grant 1983; Grigg et al. 2003; Nicol and Anderson 2006; Lovegrove and Genin 2008) and the more typical mammalian $T_{\mathrm{b}}$ of $37^{\circ}-38^{\circ} \mathrm{C}$. Even among the Eulipotyphla, hedgehogs display unusually low $T_{\mathrm{b}}$ (Whittow et al. 1977; Campbell et al. 1999). While a large body of literature exists on thermoregulation of hedgehogs, relatively little work has been published on $T_{\mathrm{b}}$ patterns of this taxon in the wild, especially in arid environments. Laboratory and semicaptive studies suggest that the European hedgehog (Erinaceus europaeus) probably undergoes the longest and deepest torpor bouts among hedgehogs (Dmi'el and Schwarz 1984; Soivio et al. 1968; Fowler and Racey 1990; Webb and Ellison 1998), but other hedgehog species also display relatively long torpor bouts characterized by low $T_{\mathrm{b}}$ (Hallam and Mzilikazi 2011; Mouhoub-Sayah et al. 2012). The four species for which $T_{\mathrm{b}}$ data are available come from a variety of climates (temperature and subtropical) and habitats (woodlands and grasslands), and all use torpor.

We recorded $T_{\mathrm{b}}$ of free-ranging desert hedgehogs (Paraechinus aethiopicus) across three seasons in a harsh desert environment. Desert hedgehogs are unusual among the hedgehogs because of their adaptations to extremely arid environments; thus, their thermoregulation is likely to be unusual as well. Given that heterothermy seems ubiquitous among the hedgehogs, we expected heterothermy in desert hedgehogs as well. However, given the unusual ecology of this species relative to other hedgehogs, we had no a priori expectations about the form of heterothermy.

\section{Methods}

\section{Study Species}

The desert hedgehog (150-600 g) is an arid-adapted insectivore found throughout the nonmountainous regions of the Arabian Peninsula and in extreme northern Africa. Relatively little is known about the natural history, behavior, and ecology of this species compared with European hedgehogs and several species and hybrids commonly kept as pets. Courtship behavior most commonly occurs during late winter and into early spring (Yamaguchi et al. 2013). They are mostly nocturnal, and seasonal activity levels of captive animals decrease considerably during midwinter (Al-Musfir and Yamaguchi 2008), and $T_{\mathrm{b}}$ appears to drop when exposed to low ambient temperatures (as cited by Corbet 1988), so it has been assumed they hibernate. It is also known that desert hedgehogs bask during cool winter days, presumably to help control $T_{\mathrm{b}}$ (Abu Baker et al. 2016)

\section{Experimental Design}

We hand captured desert hedgehogs over two sessions in sandy habitats on or near date farms of the Unizah province, Saudi Arabia $\left(26.136^{\circ} \mathrm{N}, 43.975^{\circ} \mathrm{E}\right)$. We started each capture period just after sunset in winter and around midnight in summer. The first collection period was in summer 2013 (June 2013). The second collection period was in winter 2013-2014 (November 2013). We captured 20 animals in each season.

We temporarily housed the hedgehogs in an animal facility at the Department of Zoology of King Saud University in Riyadh. We used temperature-sensitive data loggers set to record at 1 -h intervals $\left(0.0625^{\circ} \mathrm{C}\right.$ resolution, iButtons, DS1922L, $4.2 \mathrm{~g}$ with wax, Maxim Semiconductors, Dallas) to measure core $T_{\mathrm{b}}$. We did not have proper equipment available to fully calibrate data loggers. Previous experience with this model of data logger indicates that most are accurate within values claimed by the manufacturer $\left(0.5^{\circ} \mathrm{C}\right)$ and that precision within a batch is high (J. G. Boyles, personal observation). However, a weakness of this model is that a small proportion of them deviate outside these values. Therefore, before implanting the data loggers, we compared their recorded temperatures to measured air temperatures to remove any data loggers with a clear offset. Thus, we are confident that our measurements are within $\pm 0.5^{\circ} \mathrm{C}$ of actual $T_{\mathrm{b}}$ values. We then coated the data loggers with biologically inert wax and had them implanted intraperitoneally by a licensed veterinarian following standard procedures. The veterinarian implanted data loggers after anesthetizing animals with isoflurane and sutured the incision with absorbable catgut. Animals were given a long-acting, broad-spectrum antibiotic (Oxytetracycline, Pfizer) to minimize chances of postsurgery infection and were held for at least $7 \mathrm{~d}$ to ensure recovery from surgeries. Finally, to facilitate recapture, we clipped a few spines and glued (Torbot Liquid Bonding Cement, Torbot) radio transmitters (RI2B, $10 \mathrm{~g}$, Holohil Systems) to the dorsal skin. Combined, the data logger and transmitter were well below $5 \%$ body mass of all individuals. We released the animals in the same area where we had captured them and attempted to recapture them approximately 2 mo after the first capture period and 5 mo after the second capture period. The first period was completed wholly during summer. The second period began in early winter and ended in late spring/early summer. Recapture was lower during summer because hedgehogs more commonly left the area or were killed on roads. We euthanized animals using ether to retrieve data loggers. These capture procedures were conducted under permits issued by the Saudi Wildlife Authority. Experimental protocols were approved by the Animal Use and Care Committee of the University of Pretoria (ethics clearance EC02916).

We calculated basic descriptive statistics for each individual (modal, minimum, and maximum $T_{\mathrm{b}}$ ) as well as the heterothermy index (HI), which is a biologically meaningful modification of a simple standard deviation that quantifies the amount of variation around the modal $T_{\mathrm{b}}$ instead of the mean $T_{\mathrm{b}}$ (Boyles et al. 2011b) and allows for comparison of thermoregulatory patterns of species with diverse physiologies (Boyles et al. 2013). During summer, we recorded hourly air temperature $\left(T_{a}\right)$ in the shade using an iButton. We recorded $T_{\mathrm{a}}$ in the same way during the second study period but lost the data, so we downloaded air temperature from a weather station approximately $27 \mathrm{~km}$ northwest of the study site (Prince Nayef bin Abdulaziz Regional Airport). Air temperatures on the study site may therefore be slightly 
different than reported, and we make only qualitative comparisons between $T_{\mathrm{a}}$ and $T_{\mathrm{b}}$ during winter. We compared modal, minimum, and maximum $T_{\mathrm{b}}$ and $\mathrm{HI}$ values between seasons and sexes using PROC GLM in SAS University Edition (SAS Institute, Cary, NC), after verifying that the data met all assumptions of that test. We used PROC MIXED to evaluate the effect of maximum $T_{\mathrm{a}}$ on maximum $T_{\mathrm{b}}$. For all analyses with seasonal comparisons, we considered data for the first study period as summer (June 16-August 16, 2013), and we split the second study period into winter (January 7-March 15,2014) and spring (March 16-May 30, 2014). We chose to split the winter and spring data on these dates somewhat arbitrarily on the basis of a noticeable shift in thermoregulatory patterns of every individual around mid-March. This also coincides with the period of increased activity reported for this species in captivity (Al-Musfir and Yamaguchi 2008). Because the data are from the same individuals, winter and spring data are not completely independent, but we could not account for individuals in the analyses because of the inclusion of summer data, which are from different individuals. We avoid quantification of torpor patterns based on the torpor cut-off method (Boyles et al. 2011a) and use only approximate descriptions of torpor patterns for the duration of torpor bouts. The data are available from the authors for analyses associated with future meta-analyses.

\section{Results}

We successfully recovered data for five individuals (three males, two females) during the first (summer) capture session and 13 individuals (nine males, four females) during the second (winter/ spring) capture session. There was more variation in descriptors of thermoregulatory patterns among seasons than between sexes (table 1; fig. 1). Body temperatures were normally distributed when pooled by season but were clearly skewed when pooled by hour within season (fig. 2). Generally speaking, $T_{\mathrm{b}}$ 's were highest in late afternoon during summer (fig. 2). Mean modal $T_{\mathrm{b}}$ 's were significantly higher during summer $(P<0.0001)$ than spring or winter, during which time modal $T_{\mathrm{b}}$ 's were nearly identical $\left(35.8^{\circ}\right.$ vs. $35.9^{\circ} \mathrm{C} ; P=0.8890$; table 1$)$. Mean maximum $T_{\mathrm{b}}$ 's varied significantly among seasons $\left(F_{2,25}=112.2, P<0.0001\right)$ but were again similar in winter and spring $\left(37.0^{\circ}\right.$ vs. $\left.36.9^{\circ} \mathrm{C} ; P=0.5713\right)$. During summer, maximum $T_{\mathrm{b}}$ was significantly affected by maximum $T_{\mathrm{a}}\left(F_{1,212}=15.64, P=0.0001\right)$, but there was no significant effect of individual $\left(F_{4,212}=2.22, P=0.0684\right)$. Ignoring individual then, the equation for a simple regression of the effects of maximum $T_{\mathrm{a}}$ on maximum $T_{\mathrm{b}}$ is $T_{\mathrm{b}}=33.06+0.0998 T_{\mathrm{a}}\left(R^{2}=\right.$ $0.047, P=0.0012)$. The single warmest $T_{\mathrm{b}}$ recorded was $39.2^{\circ} \mathrm{C}$. Minimum $T_{\mathrm{b}}$ 's were significantly different in all seasonal comparisons $(P<0.0001$ in all comparisons $)$ in the expected order (summer minimum $T_{\mathrm{b}}>$ spring minimum $T_{\mathrm{b}}>$ winter minimum $T_{\mathrm{b}}$; table 1$)$. The single minimum $T_{\mathrm{b}}$ recorded during winter was $10.9^{\circ} \mathrm{C}$, and the tenth percentile was $14.9^{\circ} \mathrm{C}$ at 0900 hours during winter (fig. 2). During winter and spring, the lowest $T_{\mathrm{b}}$ 's were recorded early morning and were slightly out of phase with $T_{\mathrm{a}}$ (fig. 3). During summer, the lowest $T_{\mathrm{b}}$ 's were recorded just after sunrise.

Every individual commonly entered torpor during winter and spring, but none did so during summer (fig. 1). HI values were significantly different in all seasonal comparisons $(P<0.0001$ in all comparisons) in the expected order (summer $\mathrm{HI}<$ spring $\mathrm{HI}<$ winter $\mathrm{HI}$; table 1). Among all the included descriptors of thermoregulatory patterns, only $\mathrm{HI}$ values were significantly different between sexes $\left(F_{1,25}=11.33, P=0.0025\right)$ and in the season $\times$ sex interaction $\left(F_{2,25}=5.28, P=0.0122\right)$. The $\mathrm{HI}$ values for males and females were similar in summer and spring but were significantly higher for females $\left(9.45^{\circ} \mathrm{C}\right)$ than males $\left(5.85^{\circ} \mathrm{C}\right)$ in winter $(P=0.0003)$. All but 10 recorded torpor bouts were less than a day long, but the longest bout was more than $101 \mathrm{~h}$ (fig. 1; estimated conservatively excluding cooling and warming phases of the bout). Although the number of torpor bouts longer than $24 \mathrm{~h}$ was small, they appear more common among females (six bouts by four individuals) than males (four bouts by nine individuals). There were several individuals that used multiday torpor bouts well into spring, including one individual that was torpid for $\sim 50$ h during May 18-20, 2014. Similar to shorter bouts in spring and in contrast to longer bouts in winter, $T_{\mathrm{b}}$

Table 1: Summary statistics of thermoregulatory patterns in desert hedgehogs (Paraechinus aethiopicus) in Saudi Arabia

\begin{tabular}{lccccr}
\hline Season & $n$ & Modal $T_{\mathrm{b}}$ & Heterothermy index & Minimum $T_{\mathrm{b}}$ & Maximum $T_{\mathrm{b}}$ \\
\hline Summer: & & & & & \\
$\quad$ Male & 3 & $36.4 \pm .25$ & $.76 \pm .19$ & $34.0 \pm .40$ & $38.6 \pm .57$ \\
$\quad$ Female & 2 & $36.5 \pm .00$ & $.82 \pm .07$ & $34.0 \pm .84$ & $39.2 \pm .01$ \\
$\quad$ Combined & 5 & $36.5 \pm .18$ & $.78 \pm .14$ & $34.0 \pm .50$ & $38.9 \pm .52$ \\
Winter: & & & & & \\
$\quad$ Male & 9 & $35.8 \pm .23$ & $5.85 \pm 1.76$ & $13.7 \pm 2.47$ & $37.0 \pm .16$ \\
$\quad$ Female & 4 & $35.9 \pm .00$ & $9.45 \pm .69$ & $11.8 \pm .69$ & $37.0 \pm .14$ \\
$\quad$ Combined & 13 & $35.8 \pm .20$ & $6.96 \pm 2.28$ & $13.1 \pm 2.23$ & $37.0 \pm .15$ \\
Spring: & & & & & \\
$\quad$ Male & 9 & $35.9 \pm .26$ & $3.63 \pm .86$ & $22.3 \pm .32$ & $36.9 \pm .27$ \\
$\quad$ Female & 4 & $35.9 \pm .10$ & $4.75 \pm .25$ & $22.3 \pm .29$ & $36.9 \pm .28$ \\
$\quad$ Combined & 13 & $35.9 \pm .22$ & $3.98 \pm .90$ & $22.3 \pm .30$ & $36.9 \pm .26$ \\
\hline
\end{tabular}

Note. All euthermic and torpid data are included, and values are presented as means $\pm \mathrm{SD}$. $T_{\mathrm{b}}$, body temperature. 


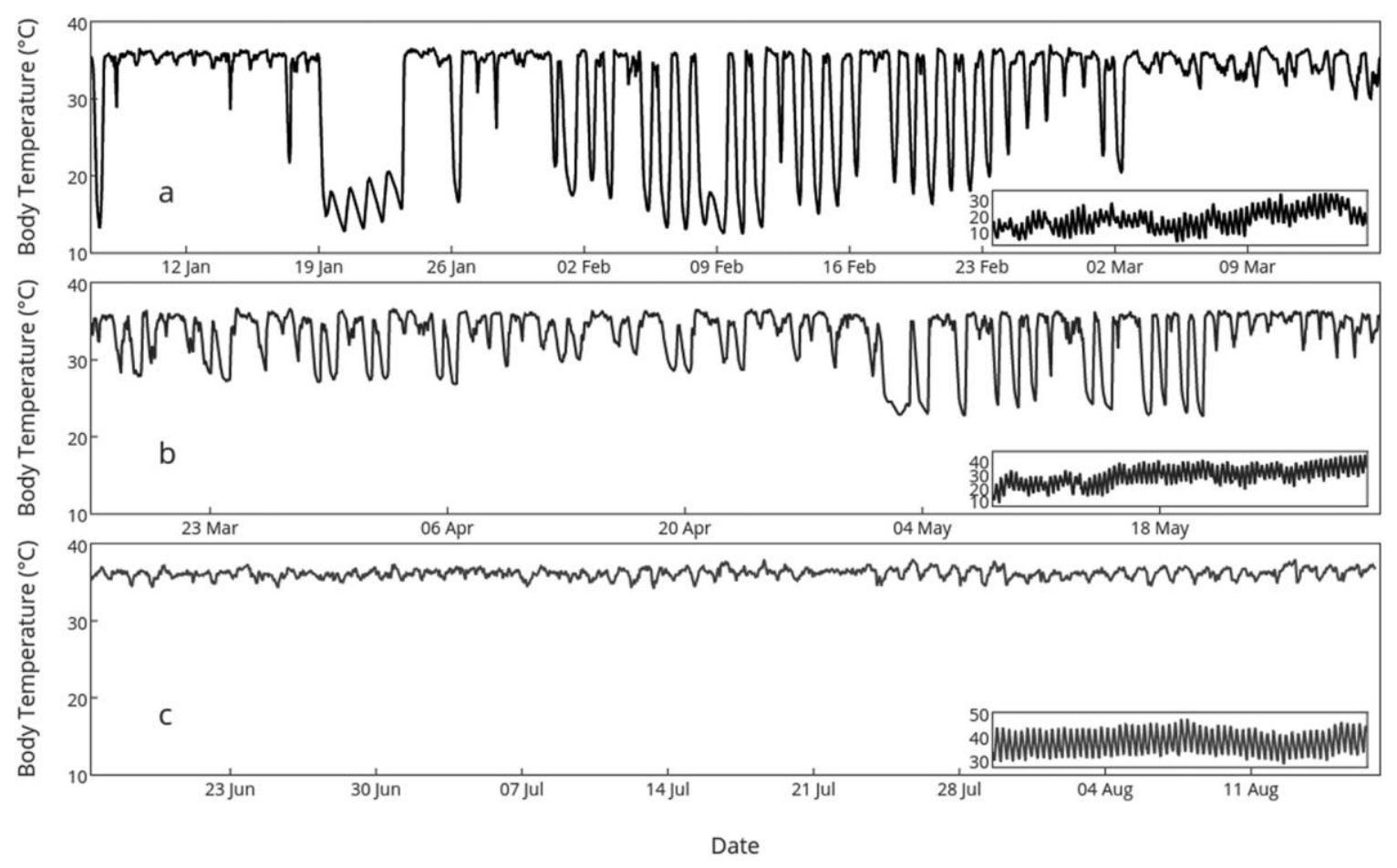

Figure 1. Representative body temperatures $\left(T_{\mathrm{b}}\right)$ of desert hedgehogs (Paraechinus aethiopicus) in Saudi Arabia during winter (January 7March 15, 2014; a), spring (March 16-May 30, 2014; b), and summer (June 16-August 16, 2013). The temperature tracing depicted for winter was from a female and chosen to demonstrate both the normal pattern of $T_{\mathrm{b}}$ (as seen during most of February) and the longest torpor bout recorded in any individual (during mid-January). Data are $T_{\mathrm{b}}$ 's, and insets are ambient temperatures for the same periods $(X$-axes are not labeled for clarity). Note the different scales on the $Y$-axes of the insets.

remained above $22^{\circ} \mathrm{C}$ during these long spring torpor bouts. The lowest $T_{\mathrm{a}}$ recorded at the airport during any of these spring bouts was $22^{\circ} \mathrm{C}$.

At some point during midwinter, nearly every individual went through a period of several days to several weeks with low nighttime $T_{\mathrm{b}}$ 's but short torpor bouts (fig. 3). While we did not have $T_{\mathrm{a}}$ data from the site and specifically from within the burrows used by these animals, minimum $T_{\mathrm{b}}$ 's often approached (and were occasionally below) $T_{\mathrm{a}}$ recorded at a nearby weather station. Unfortunately, without $T_{\mathrm{a}}$ data from the site, it is difficult to quantitatively analyze the $T_{\mathrm{b}}-T_{\mathrm{a}}$ differential.

\section{Discussion}

The data on $T_{\mathrm{b}}$ patterns reported here are some of the first for a small desert mammal across multiple seasons. Desert hedgehogs maintain relatively low normothermic $T_{\mathrm{b}}$ 's during all seasons, with summer modal $T_{\mathrm{b}}$ 's of only $36.5^{\circ} \mathrm{C}$ (table 1 ). There was no indication of torpor during summer, but short torpor bouts with low $T_{\mathrm{b}}$ 's $\left(<15^{\circ} \mathrm{C}\right)$ were common in winter, and short torpor bouts with moderate $T_{\mathrm{b}}$ 's $\left(>22^{\circ} \mathrm{C}\right)$ were common in spring, when reproductive activity increases (Alagaili et al., forthcoming). Mammals often display larger variation in $T_{\mathrm{b}}$ in winter than summer (Chappell and Bartholomew 1981; Mustonen et al. 2007; Boyles et al. 2013), but the combination of strict homeothermy during summer and short torpor bouts during winter is rarely reported for mammals (Ruf et al. 1989; Mzilikazi and Lovegrove 2004). More commonly discussed in the literature are species that (1) maintain homeothermy (or rarely use heterothermy) during summer and hibernate during winter (e.g., Zervanos and Salsbury 2003; Levesque and Tattersall 2010; Whiteman et al. 2015) or (2) use some form of heterothermy in all seasons (e.g., Geiser and Baudinette 1987; Bartels et al. 1998; Dzal and Brigham 2013). It is unclear whether these patterns are more common or are simply overrepresented in the literature because of geographic biases of researchers (McKechnie and Mzilikazi 2011). It seems logical that use of daily torpor during winter and homeothermy during summer should be common, especially among subtropical and desert species inhabiting environments that are hot during summer and either cold or offer variable food sources during winter. Among many likely candidates are those known to use short torpor bouts during winter but for which summer data are not available (e.g., Boyles et al. 2012; Cory Toussaint et al. 2010).

The daily cycle of $T_{\mathrm{b}}$ 's was slightly out of phase with $T_{\mathrm{a}}$ during winter and spring, with $T_{\mathrm{b}}$ 's still decreasing as $T_{\mathrm{a}}$ 's were increasing in the morning (figs. 2,3). The smallest $T_{\mathrm{b}}-T_{\mathrm{a}}$ differentials were often several hours after the minimum $T_{a}$ was recorded on a given day. This pattern was most pronounced on days when hedgehogs used torpor during winter, because it appeared that they allowed $T_{\mathrm{b}}$ to drop until the increasing heat of morn- 

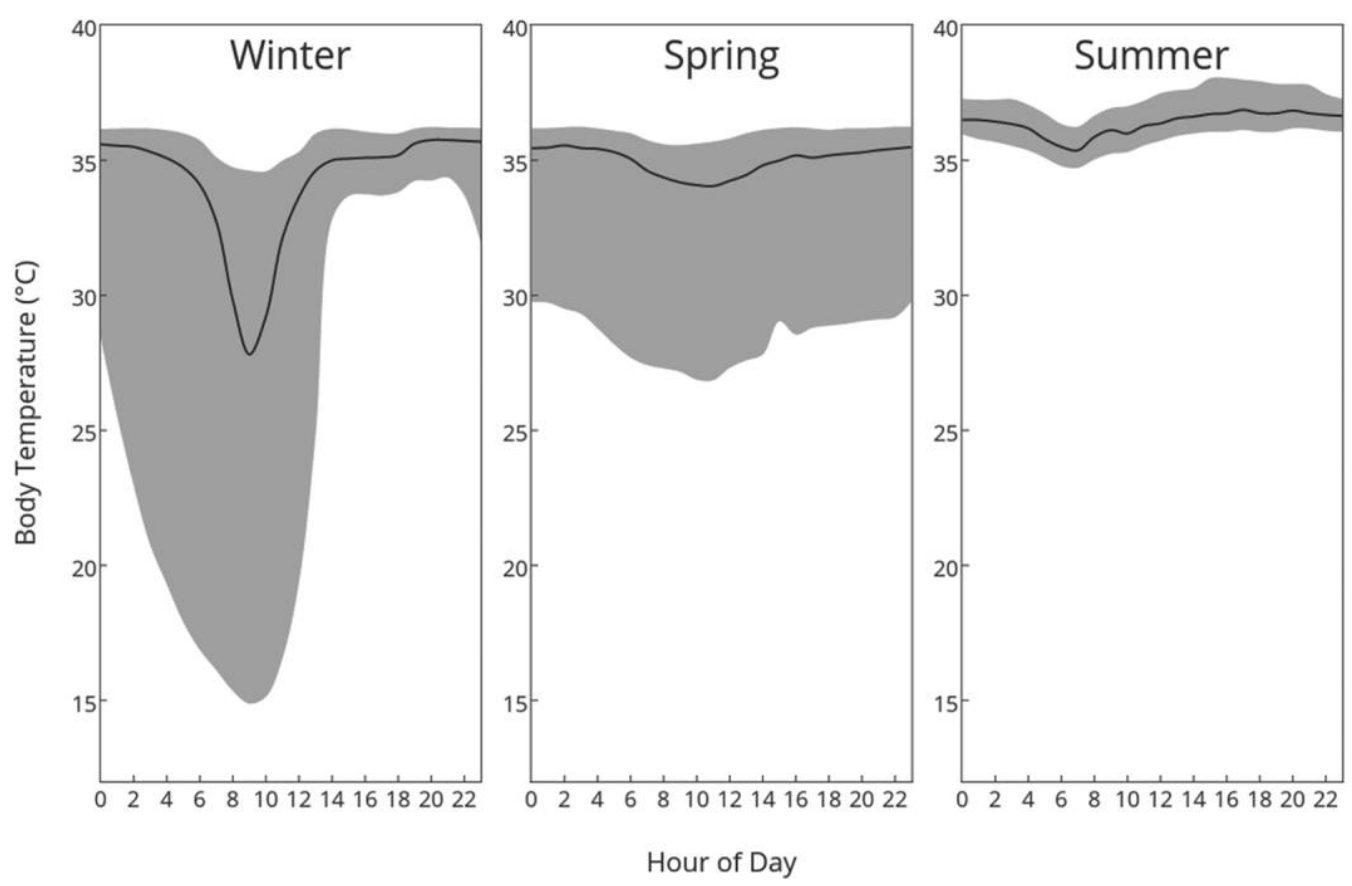

Figure 2. Body temperatures of desert hedgehogs (Paraechinus aethiopicus) across the day in winter, spring, and summer. Lines represent median $T_{\mathrm{b}}$ 's, and shaded areas are bounded by the tenth and ninetieth percentiles.

ing pushed it higher. The cyclical pattern was also seen during multiday torpor bouts but to a muted degree (e.g., figs. 1, 3); it is unclear whether $T_{\mathrm{b}}$ cycles during multiday torpor are driven by intrinsic or extrinsic factors. Occasionally, $T_{\mathrm{b}}$ dropped below recorded $T_{\mathrm{a}}$ during torpor bouts. We do not have behavioral observations of these animals during the periods when we were recording $T_{\mathrm{b}}$, so we cannot distinguish between two possible explanations for this pattern: either the weather station temperatures were slightly different than those at the study site, or hedgehogs were using burrows or other structures that buffered $T_{\mathrm{a}}$ (e.g., dead woody material, which we know they do use). Previous work on captive desert hedgehogs confirms that they are nocturnal and inactive during the day (Al-Musfir and Yamaguchi 2008), so the recorded $T_{\mathrm{b}}$ pattern is not surprising. From an energetic standpoint, it would be most efficient to cool into torpor as quickly as possible and remain in torpor as long as possible. Behavioral observations will be useful to determine whether the quick increases in $T_{\mathrm{b}}$ in the morning are related to adaptive behavior (e.g., basking) or reflect minimum available environmental temperatures, even in burrows.

Despite extensive laboratory work on thermoregulation of desert mammals, data on summer $T_{\mathrm{b}}$ patterns of small desert mammals are surprisingly rare. During summer, most variation in $T_{\mathrm{b}}$ occurs above normothermy. The diurnal species studied in the field occasionally reach $T_{\mathrm{b}}$ 's greater than $41^{\circ} \mathrm{C}$ (Chappell and Bartholomew 1981; Elvert et al. 1999; Alagaili et al. 2017). The few nocturnal species studied in the field do show regular increases in $T_{\mathrm{b}}$ above normothermy but reach maximum $T_{\mathrm{b}}$ 's several degrees lower than diurnal species (Elvert et al. 1999; this study). It remains unclear whether these increases in $T_{\mathrm{b}}$ represent an adaptive water conservation technique or are simply a biophysical reality for a small animal in a hot environment (Walsberg 2000).

The torpor patterns we recorded for desert hedgehogs during winter are intermediate to those classically described for hibernators and daily heterotherms (Geiser and Ruf 1995). The duration of most torpor bouts we recorded for hedgehogs was similar to daily torpor bouts used by daily heterotherms, but torpid $T_{\mathrm{b}}$ 's were regularly lower than those of daily heterotherms, especially for an animal that weighs 150-600 g (Geiser and Ruf 1995). Furthermore, while most torpor bouts were less than $24 \mathrm{~h}$ long, several individuals underwent bouts of 2,3 , or $4 \mathrm{~d}$, which is unusual among daily heterotherms. Body temperatures often approached $T_{\mathrm{a}}$, suggesting that metabolic rates must have been low (Geiser and Mzilikazi 2011). Conversely, while minimum torpid $T_{\mathrm{b}}$ 's were similar to those of some hibernators, torpor bouts were unpredictable, and no individual ever maintained a pattern of long torpor bouts interrupted by occasional euthermic periods, as is characteristic of hibernators. The pattern we recorded in desert hedgehogs is unusual among the hedgehogs studied to date, which show longer and more predictable torpor bouts during winter (Fowler and Racey 1990; Hallam and Mzilikazi 2011; Mouhoub-Sayah et al. 2012). This may relate to the more arid habitat of desert hedgehogs compared with the other species and the unpredictability of food resources in this habitat.

In the strictest sense, one could argue that the desert hedgehog is an unusual species that mixes physiological characteristics of hibernators and daily heterotherms, bringing to three the number of genera known to use such a pattern of torpor. Along with desert hedgehogs, Patagonian opossums (Lestodelphys halli; Geiser and 


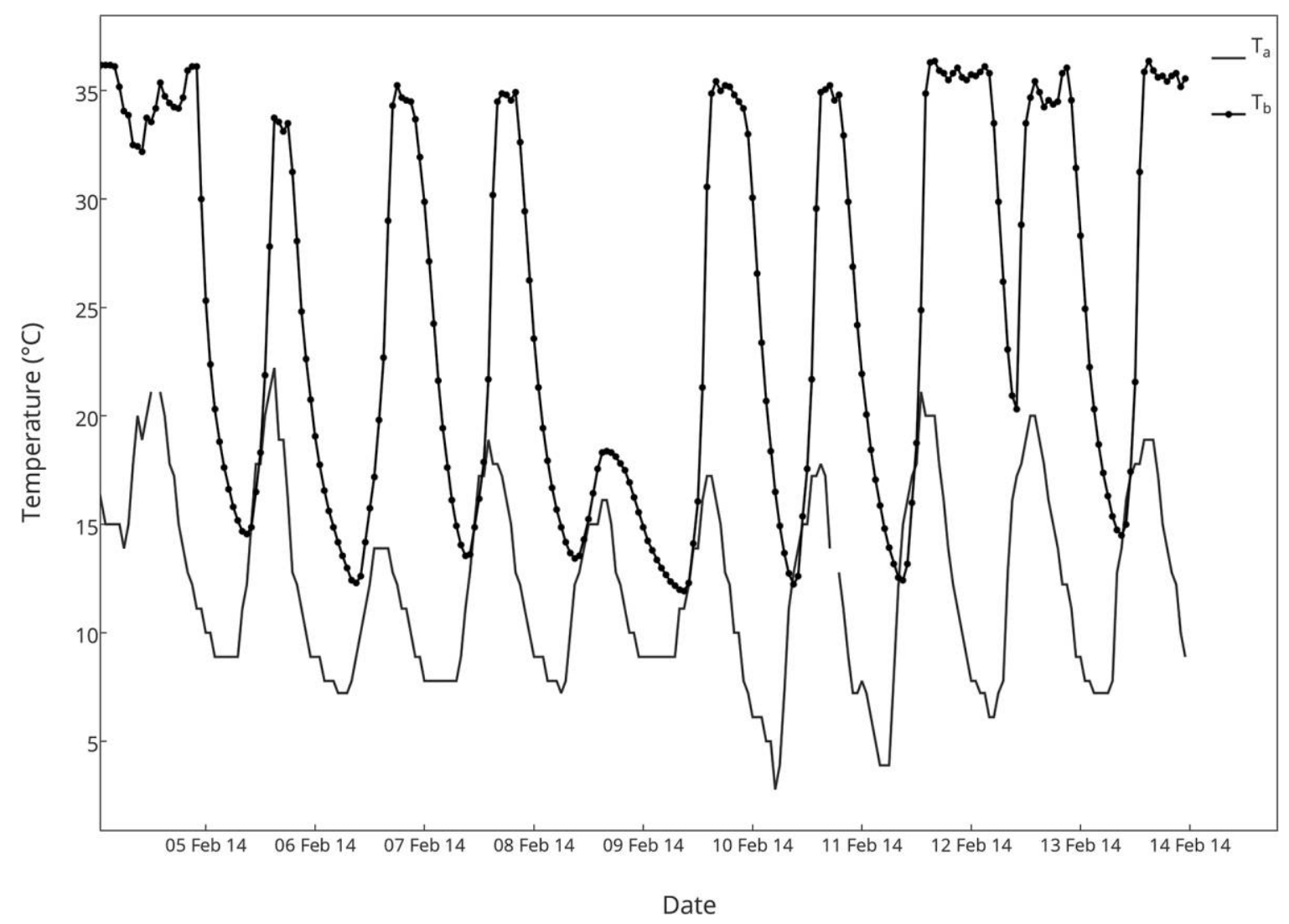

Figure 3. Representative winter body temperature $\left(T_{\mathrm{b}}\right)$ of a male desert hedgehog (Paraechinus aethiopicus) over a 10-d period during February $4-13,2014$. Ambient temperature $\left(T_{\mathrm{a}}\right)$ comes from a weather station approximately $27 \mathrm{~km}$ northwest of the study site (Prince Nayef bin Abdulaziz Regional Airport). Body temperatures were similar for females, but the $T_{\mathrm{b}}-T_{\mathrm{a}}$ differentials were generally smaller during deep torpor than seen in males.

Martin 2013) and several sengis in the genus Myurus (also known as elephant shrews and locally as klaasneus) meet this strict criterion (Mzilikazi and Lovegrove 2004; Geiser and Mzilikazi 2011; Boyles et al. 2012). While ancestral hedgehogs appear in the fossil record shortly after the Cretaceous-Paleogene extinction event (O'Leary et al. 2013), the radiation of modern hedgehog genera was sudden and much more recent (Bannikova et al. 2014). The ecology of desert hedgehogs suggests they are derived from more temperate and semiarid species, so the unusual thermoregulatory pattern might also be derived. If so, this would be interesting because it has been suggested that this unusual pattern may be representative of an ancestral state in sengis and opossums (Geiser and Martin 2013).

A more liberal interpretation of the pattern of torpor we recorded in desert hedgehogs is that this pattern is not truly unique and represents another point along a gradient of thermoregulatory patterns (Boyles et al. 2013; van Breukelen and Martin 2015). If so, it strengthens the argument that greater variation in thermoregulatory patterns exists than traditionally realized and that desert hedgehogs are simply another exception to a strict classification scheme that separates daily heterotherms and hibernators (Canale et al. 2012). It is true that most arguments for a thermoregulatory continuum are based on measurements of
$T_{\mathrm{b}}$, and other characteristics of thermoregulation (e.g., metabolic rates) need to be detailed more thoroughly in species with $T_{\mathrm{b}}$ patterns intermediate to daily heterotherms and hibernators.

The thermoregulatory pattern we measured herein adds interesting variation to thermoregulatory patterns seen among the Erinaceidae (hedgehogs and gymnures) and Eulipotypha and further solidifies suggestions that these taxa are interesting for thermoregulatory studies (e.g., Lovegrove 2012b). Even with the Erinaceidae, the opportunities to test predictions of evolutionary and ecological drivers of thermoregulation abound. For example, the divergence of gymnures (subfamily Galericinae) appears quite old, happening in the middle to late Eocene, while the extant hedgehogs radiated recently (Bannikova et al. 2014). Thus, within this single family, there is a diverse and contrasting evolutionary history (Bannikova et al. 2014). While conflated with phylogeny, there is also variation in habitat (forest, grassland, and desert) and latitude (tropical to high temperate) within this family. Finally, there is wide variation in thermoregulatory patterns, ranging from apparent homeothermy in lesser gymnures (Hylomys suillus; Genoud and Ruedi 1996) to deep hibernation in temperate hedgehogs. Despite the logistical difficulties associated with studying many species in this taxon, we encourage further study of thermoregulatory patterns of the Eulipotyphla to inform 
our understanding of evolution of thermoregulation in laurasiatherians, eutherians, and mammals as a whole.

\section{Acknowledgments}

This project was financially supported by the Deanship of Scientific Research at the King Saud University through the research group (project RGP_VPP_020), the South African National Research Foundation (grant 64756), and the University of Pretoria.

\section{Literature Cited}

Abu Baker M.A., N. Reeve, I. Mohedano, A.A.T. Conkey, D.W. MacDonald, and N. Yamaguchi. 2016. Caught basking in the winter sun: preliminary data on winter thermoregulation in the Ethiopian hedgehog, Paraechinus aethiopicus, in Qatar. I Arid Environ 125:52-55.

Alagaili A.N., N.C. Bennett, O.B. Mohammed, and D.W. Hart. Forthcoming. The reproductive biology of the Ethiopian hedgehog, Paraechinus aethiopicus, from central Saudi Arabia: the role of rainfall and temperature. J Arid Environ.

Alagaili A.N., N.C. Bennett, O.B. Mohammed, I.S. Zalmout, and J.G. Boyles. 2017. Body temperature patterns of a small endotherm in an extreme desert environment. L Arid Environ 137:16-20.

Al-Musfir H.M. and N. Yamaguchi. 2008. Timings of hibernation and breeding of Ethiopian hedgehogs, Paraechnius aethiopicus, in Qatar. Zool Middle East 45:3-10.

Bannikova A.A., V.S. Lebedev, A.V. Abromov, and V.V. Rozhnov. 2014. Contrasting evolutionary history of hedgehogs and gymnures (Mammalia: Erinaceomorpha) as inferred from a multigene study. Biol I Linn Soc Lond 112:499519.

Bartels W., B.S. Law, and F. Geiser. 1998. Daily torpor and energetics in a tropical mammal, the northern blossum-bat Macroglossus minimus (Megachiroptera). L Comp Phvsiol B 168:233-239.

Bininda-Emonds O.R.P., M. Cardillo, K.E. Jones, R.D.E. MacPhee, R.M.D. Beck, R. Grenyer, S.A. Prices, R.A. Vos, J.L. Gittleman, and A. Purvis. 2007. The delayed rise of present-day mammals. Nature 446:507-512.

Boyles J.G., B. Smit, and A.E. McKechnie. 2011a. Does use of the torpor cut-off method to analyze variation in body temperature cause more problems than it solves? LTherm Biol 36:373-375.

2011b. A new comparative metric for estimating heterothermy in endotherms. Physiol Biochem Zool 84:115123.

Boyles J.G., B. Smit, C.L. Sole, and A.E. McKechnie. 2012. Body temperature patterns in two syntopic elephant shrew species during winter. Comp Biochem Physiol A 161:89-94.

Boyles J.G., A.B. Thompson, A.E. McKechnie, E. Malan, M.M. Humphries, and V. Careau. 2013. A global heterothermic continuum in mammals. Glob Ecol Biogeogr 22:1029-1039.
Campbell K.L., I.W. McIntyre, and R.A. MacArthur. 1999. Fasting metabolism and thermoregulatory competence of the star-nosed mole, Condylura cristata (Talpidae: Condylurinae). Comp Biochem Physiol A 123:293-298.

Canale C.I., D.L. Levesque, and B.G. Lovegrove. 2012. Tropical heterothermy: does the exception prove the rule or force a re-definition? Pp. 29-40 in T. Ruf, C. Bieber, W. Arnold, and E. Millesi, eds. Living in a seasonal world: thermoregulatory and metabolic adaptations. Springer, Berlin.

Chappell M.A. and G.A. Bartholomew. 1981. Activity and thermoregulation of the antelope ground squirrel (Ammospermophilus leucurus) in winter and summer. Physiol Zool 54: 215-223.

Corbet G.B. 1988. The family Erinaceidae: a synthesis of its taxonomy, phylogeny, ecology and zoogeography. Mamm Rev 18:117-172.

Cory Toussaint D., A.E. McKechnie, and M. van der Merwe. 2010. Heterothermy in free-ranging male Egyptian freetailed bats (Tadarida aegyptiaca) in a subtropical climate. Mamm Biol 75:466-470.

Dmi'el R. and M. Schwarz. 1984. Hibernation patterns and energy expenditure in hedgehogs from semi-arid and temperate habitats. L Comp Phvsiol B 155:117-123.

Douady C.J., P.I. Chatelier, O. Madsen, W.W. de jong, F. Catzeflis, M.S. Springer, and M.J. Stanhope. 2002. Molecular phylogenetic evidence confirming the Eulipotyphla concept and in support of hedgehogs as the sister group to shrews. Mol Phylogenet Evol 25:200-209.

Douady C.J. and E.J.P. Douzery. 2003. Molecular estimation of eulipotyhlan divergence times and the evolution of "Insectivora." Mol Phylogenet Evol 28:285-296.

Dzal Y.A. and R.M. Brigham. 2013. The tradeoff between torpor use and reproduction in little brown bats (Myotis lucifugus). L Comp Physiol B 183:279-288.

Elvert R., N. Kronfeld, T. Dayan, A. Haim, N. Zisapel, and G. Heldmaier. 1999. Telemetric field studies of body temperature and activity rhythms of Acomys russatus and A. cahirinus in the Judean Desert of Isreal. Oecologia 119:484-492.

Fowler P.A. and P.A. Racey. 1990. Daily and seasonal cycles of body temperature and aspects of heterothermy in the hedgehog Erinaceus europaeus. L Comp Physiol B 160:299-307.

Geiser F. 1998. Evolution of daily torpor and hibernation in birds and mammals: importance of body size. Clin Exp Pharmacol Physiol 25:736-740.

Geiser F. and R.V. Baudinette. 1987. Seasonality of torpor and thermoregulation in three dasyurid marsupials. LComp Physiol B 157:335-344.

Geiser F. and G.M. Martin. 2013. Torpor in the Patagonian opossum (Lestodelphys halli): implications for the evolution of daily torpor and hibernation. Naturwissenschaften 100:975-981.

Geiser F. and N. Mzilikazi. 2011. Does torpor of elephant shrews differ from that of other heterothermic mammals? LMammal 92:452-459.

Geiser F. and T. Ruf. 1995. Hibernation versus daily torpor in mammals and birds: physiological variables and classification of torpor patterns. Physiol Zool 68:935-966. 
Genoud M. and M. Ruedi. 1996. Rate of metabolism, temperature regulations, and evaporative water loss in the lesser gymnure Hylomys suillus (Insectivora, Mammalia). L Zool (Lond) 240:309-316.

Grant T.R. 1983. Body temperatures of free-ranging platypuses, Ornithorhyncus anatinus (Monotremata), with observations of their use of burrows. Aust I Zool 31:117-122.

Grigg G.C., L.A. Beard, J.A. Barnes, L.I. Perry, G.J. Fry, and M. Hawkins. 2003. Body temperature in captive long-beaked echidnas (Zaglossus bartoni). Comp Biochem Physiol A 136:911-916.

Hallam S.L. and N. Mzilikazi. 2011. Heterothermy in the southern African hedgehog, Atelerix frontalis. LComp Physiol B 181:437445.

Hallström B.M. and A. Janke. 2010. Mammalian evolution may not be strictly bifurcating. Mol Biol Evol 27:2804-2816.

Król E. 1994. Metabolism and thermoregulation in the eastern hedgehog Erinaceus concolor. LComp Phvsiol B 164:503-507.

Levesque D.L. and G.J. Tattersall. 2010. Seasonal torpor and normothermic energy metabolism in the eastern chipmunk (Tamias striatus). L Comp Phvsiol B 180:279-292.

Lovegrove B.G. 2012a. The evolution of endothermy in Cenozoic mammals: a plesiomoprhic-apomorphic continuum. Biol Rev 87:128-162.

. 2012b. A single origin of heterothermy in mammals. Pp. 3-11 in T. Ruf, C. Bieber, W. Arnold, and E. Millesi, eds. Living in a seasonal world: thermoregulatory and metabolic adaptations. Springer, Berlin.

Lovegrove B.G. and F. Genin. 2008. Torpor and hibernation in a basal placental mammal, the lesser hedgehog tenrec Echinops telfairi. L Comp Physiol B 178:691-698.

Lovegrove B.G., J. Raman, and M.R. Perrin. 2001. Heterothermy in elephant shrews, Elephantulus spp. (Macroscelidea): daily torpor or hibernation? L Comp Physiol B 171:1-10.

McKechnie A.E. and N. Mzilikazi. 2011. Heterothermy in Afrotropical mammals and birds: a review. Integr Comp Biol 51:349-363.

Mouchaty S.K., A. Gullberg, A. Janke, and U. Arnason. 2000. The phylogenetic position of the Talpidae within Eutheria based on analysis of complete mitochondrial sequences. Mol Biol Evol 17:60-67.

Mouhoub-Sayah C., J.-P. Robin, A. Malan, P. Pévet, and M. Saboureau. 2012. Patterns of body temperature change in the Algerian hedgehog (Atelerix algirus) during autumn and winter. Pp. 307-316 in B.G. Lovegrove and A.E. McKechnie, eds. Hypometabolism in animals: hibernation, torpor and cryobiology. Interpak, Pietermaritzburg.

Mustonen A.-M., J. Asikainen, K. Kauhala, T. Paakkonen, and P. Nieminen. 2007. Seasonal rhythms of body temperature in the free-ranging raccoon dog (Nyctereutes procyonoides) with special emphasis on winter sleep. Chronobiol Int 24:1095-1107.

Mzilikazi N. and B.G. Lovegrove. 2004. Daily torpor in freeranging rock elephant shrews, Elephantulus myurus: a yearlong study. Physiol Biochem Zool 77:285-296.

Nicol S. and N.A. Anderson. 2006. Body temperature as an indicator of egg-laying in the echidna, Tachyglossus aculeatus. I Therm Biol 31:483-490.

O’Leary M.A., J.I. Bloch, J.J. Flynn, T.J. Gaudin, A. Giallombardo, N.P. Giannini, S.L. Golberg, et al. 2013. The placental mammal ancestor and the post-K-Pg radiation of placentals. Science 339:662-667.

Ruf T., S. Steinlechner, and G. Heldmaier. 1989. Rhythmicity of body temperature and torpor in the Djungarian hamster, Phodopus sungorus. Pp. 53-62 in A. Malan and B. Canguilhem, eds. Living in the cold: 2nd international symposium. Libbey, London.

Shkolnik A. and K. Schmidt-Nielsen. 1976. Temperature regulation in hedgehogs from temperate and desert environments. Phvsiol Zool 49:56-64.

Soivio A., H. Tähti, and R. Kristoffersson. 1968. Studies on the periodicity of hibernation in the hedgehog (Erinaceus europaeus L.). III. Hibernation in a constant ambient temperature of $-5^{\circ} \mathrm{C}$. Ann Zool Fennici 5:224-226.

van Breukelen F. and S.L. Martin. 2015. The hibernation continuum: physiological and molecular aspects of metabolic plasticity in mammals. Physiology 30:273-281.

Walsberg G.E. 2000. Small mammals in hot deserts: some generalizations revisited. BioScience 50:109-120.

Webb P.I. and J. Ellison. 1998. Normothermy, torpor, and arousal in hedgehogs (Erinaceus europaeus) from Dunedin. N Z I Zool 25:85-90.

Whiteman J.P., H.J. Harlow, G.M. Durner, R. AndersonSprecher, S.E. Albeke, E.V. Regehr, S.C. Amstrup, and M. BenDavid. 2015. Summer declines in activity and body temperature offer polar bears limited energy savings. Science 349: 295-298.

Whittow G.C., E. Gould, and D. Rand. 1977. Body temperature, oxygen consumption, and evaporative water loss in a primitive insectivore, the moon rat, Echinosorex gymnurus. L Mammal 58:233-235.

Yamaguchi N., A. Al-Hajri, and H. Al-Jabiri. 2013. Timing of breeding in free-ranging Ethiopian hedgehogs, Paraechinus aethiopicus, from Qatar. LArid Environ 99:1-4.

Zervanos S.M. and C.M. Salsbury. 2003. Seasonal body temperature fluctuations and energetic strategies in free-ranging eastern woodchucks (Marmota monax). LMammal 84:299310 . 